diarrhoea developed in 23 , transient diarrhoea in 10 , and a tendency to constipation in 5 . Only 8 of the patients in the whole group were disappointed in their bowel condition, 3 because they now suffered from constipation. No fewer than 55 of the patients were actually pleased with their increased frequency of bowel action. The same authors collected data from 25 papers on the incidence of diarrhoea after vagotomy and found an overall figure of about $2 \%$ of troublesome diarrhoea.

The cause (or perhaps causes) of this post-vagotomy diarrhoea, which is often episodic, remains a mystery. It is tempting to blame the denervation of the rest of the gastrointestinal tract and its adnexae which must inevitably accompany total division of the main vagal tracts as they enter the abdomen. Yet extensive investigations have failed to show convincing evidence of disturbed biliary, ${ }^{10} 11$ pancreatic, ${ }^{12}$ or small-intestinal function. ${ }^{13} 14$ Nor have many careful studies, both clinical and experimental, shown any significant metabolic, absorptive, or radiological differences in either men or dogs undergoing total vagal division or selective vagotomy in which either the coeliac or the hepatic or both these branches of the vagus have been preserved. ${ }^{10} 11$ 15-18 In spite of these findings several surgeons have staunchly advocated the preservation of the coeliac and hepatic tracts of the vagus as a method of preventing post-vagotomy diarrhoea. In Great Britain Mr. Harold Burge has long championed this cause, and in this issue of the B.M.F. (page 481) he and his colleagues put forward a strong case for bilateral selective vagotomy. And they add: "We believe it more reasonable to think that post-vagotomy diarrhoea is caused by denervation of organs other than the stomach rather than by denervation of the stomach itself. Because no functional disturbance of these extragastric organs can be found after total abdominal vagotomy, it must not be concluded that when denervated they are not to blame for this complication." This contribution will give food for thought and perhaps encourage still further studies, both clinical and experimental, in this important field.

\section{Nail-gun Injuries}

Working at his desk on the eleventh storey, a bank clerk felt a sudden piercing pain in the left arm and chest. Looking down, he saw blood and collapsed. Investigation showed that he had been hit in the chest with a stud fired by a blank cartridge from a building site across the street. This type of accident has been reported from Germany, ${ }^{12}$ America, ${ }^{3}$ the Soviet Union, ${ }^{4}$ and Great Britain, ${ }^{5-11}$ where cartridgeoperated fixing-tools (nail guns) have been in common use for about 14 years. A letter in our correspondence columns (p. 511) draws attention to the lack of effective measures for the control of these dangerous tools.

\footnotetext{
Staudacher, F. X., Mschr. Unfallheilk., 1960, 63, 17.

Russe, O., Klin. Med. (Wien), 1960, 15, 220.

Mage, S., and Sze, K. C., New Engl. F. Med., 1962, 267, 1020

Zverev, A. F., Vestn. Khir., 1964, 93, 92.

- Klenerman, L., Brit. med. F., $1961,2,1785$.

- Oldfield, M. C., Brit. med. \%., 1962, 1, 262

Wilson, P. J. E., Brit. med. F., 1962, 1, 341.

- Cragg, J., Brit. med. F., 1967, 4, 784.

- McMillan, I. K. R., Brit. med. f., 1968, 1, 181

10 Spencer G. T., Brit. med. ₹., 1968, 1, 181 .

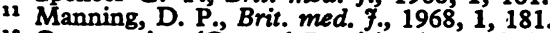

12 Construction (General Provisions) Regulations, S.I. 1580/1961; Working Places Regulations, S.I. 94/1966. H.M.S.O.

18 Wander, R., The Illustrated Carpenter and Builder, 1967, 156, 194.

14 Ministry of Works Advisory Leaflet No. 53, 1962. H.M.S.O.

1s Specification for Cartridge-Operated Fixing Tools, 1966, British StanSpecification
dards 4078 .
}

Some of these guns have a muzzle velocity of up to $1,400 \mathrm{ft}$. $(430 \mathrm{~m}$.) $/ \mathrm{sec}$ - - a $0.22 \mathrm{in}$. (6 mm.) rifle has a muzzle velocity of about $1,145 \mathrm{ft}$. $(350 \mathrm{~m}$.)/sec. - and the injuries which have been reported are often severe, because the sharp, highvelocity projectiles, designed to penetrate masonry or wood, may enter deeply into the thorax or abdomen. They can do so after traversing a $10-\mathrm{cm}$. brieze wall ${ }^{3}$ or a brick wall (travelling in the mortar between bricks), ${ }^{9}$ or after ricocheting off hard material such as concrete. ${ }^{6}$

In Britain nearly all the accidents reported from these tools have resulted from activities on building sites, and the victims have usually been workers on the sites. The responsibility for the enforcement of statutory safety measures in this area rests with the Factory Inspectorate of the Ministry of Labour, but at present the only statutory requirement is that explosives should be handled or used by, or under the immediate control of, a competent person. ${ }^{12}$ It would seem that such a regulation was intended for quite different circumstances. Furthermore, it is possible that cartridge-operated fixing-tools may be used on premises that are not legally "factories" and to which the requirements of the Factories Act do not apply. If such use is widespread it may be asked whether such activities are covered by any wider legislation.

R. Wander ${ }^{13}$ has recently reviewed the safety of these appliances, and the Ministry of Works has issued an advisory leaflet. ${ }^{14}$ The British Standards Institute has issued a Specification for Cartridge-operated Fixing Tools. ${ }^{15}$ It recommends that the tools should incorporate a splinter guard to withstand ricochet and to retain flying pins, that tools should fire only when the barrel and splinter guard are pressed against the fixing surface with a pressure of not less than $5 \mathrm{~kg}$., and that they should not fire when the angle formed between the perpendicular and the axis of the tool is greater than $7^{\circ}$. An appendix to the specification gives commonsense recommendations for the use of cartridge-operated fixing-tools. The pins should not be driven into brittle or hard materials such as vitreous-faced bricks or hardened steel. They should not be driven into structures where there is a risk of their passing through, unless special precautions are taken. Operators of fixing-tools should receive adequate training, and persons less than 18 years of age should not be permitted to use them.

Such a British Standard has no legal force. The recent reports of accidental injury pose the question whether the time has come for stricter legislative control. The recommendations of the British Standard would form a useful basis for a statutory code.

\section{Dental Anaesthesia}

Over the past 20 years it has become apparent that the arrangements for general anaesthesia in dentists' surgeries are sometimes less than perfect. This uneasiness coincided with the explosive post-war growth of interest in anaesthesia in general, and, as a result, general anaesthesia for dental surgery received a close look by experts in anaesthesia who brought to it standards of comparison and assessment which were hitherto unknown. General anaesthesia for dentistry, like anaesthesia for other kinds of surgery, had been regarded for nearly 100 years as a matter of technique alone, the acquisition of which was all that was necessary for a satisfactory performance. It is now accepted that anaesthetists must, in addition, be knowledgeable about a wide range of basic medical subjects, of which physiology and pharmacology are two of the most 